\title{
MÉTODO DE SELEÇÃO E IDENTIFICAÇÃO DE FONTES DE RESISTÊNCIA À MURCHA DO EUCALIPTO CAUSADA POR Ceratocystis fimbriata ${ }^{1}$
}

\author{
Reginaldo Gonçalves Mafia², Acelino Couto Alfenas ${ }^{3}$, Eraclides Maria Ferreira ${ }^{4}$ e \\ Daniel Henrique Breda Binoti ${ }^{5}$
}

\begin{abstract}
RESUMO - Este trabalho teve como objetivo desenvolver um método de seleção e identificar fontes de resistência à murcha do eucalipto causada por Ceratocystis fimbriata. A inoculação de $5 \mathrm{ml}$ de inóculo (2,5 x $10^{4}$ esporos $\left./ \mathrm{ml}\right)$ do patógeno em um ferimento no coleto de mudas com 60 dias de idade foi o método mais eficiente na reprodução dos sintomas da doença. Para este método, a severidade da doença e a mortalidade de plantas em função do tempo após a inoculação foram avaliadas. Um período de 30 dias após a inoculação foi suficiente para reproduzir os sintomas da doença. O protocolo de inoculação desenvolvido apresentou alto rendimento (400 plantas/ h) e menor consumo de espaço, quando comparado com outros métodos, principalmente pelo fato de possibilitar a inoculação de mudas jovens de eucalipto, entre 60 e 90 dias. Na segunda etapa do trabalho, a resistência interespecífica do eucalipto a C. fimbriata foi avaliada usando as espécies Eucalyptus camaldulensis, E. dunnii, E. grandis, E. pellita, E. saligna, E. tereticornis e E. urophylla. Houve segregação da resistência para todas as espécies e de acordo com o local de origem da população. Para E. urophylla, por exemplo, ocorreram as maiores variações entre o número de indivíduos resistentes e suscetíveis à doença. Essas variações podem estar ligadas com a procedência das sementes e com as características do programa de melhoramento genético.

Palavras-chave: Eucalyptus, Seleção de genótipos e Resistência.
\end{abstract}

\section{SCREENING METHOD AND IDENTIFICATION OF RESISTANCE SOURCES TO EUCALYPTUS WILT CAUSED BY Ceratocystis fimbriata}

\begin{abstract}
The objective of this work was to develop a screening method and to identify resistance source to eucalyptus wilt caused by Ceratocystis fimbriata. The inoculation of $5 \mathrm{ml}$ of pathogen inoculum $(2.5 \times$ $10^{4}$ spores $/ \mathrm{ml}$ ) on the wound root crown of seedlings at 60 days of age was the most efficient method to reproduce the disease symptoms. For this method, disease severity and plant mortality in function of time after inoculation were assessed. A 30-day period after inoculation was sufficient to reproduce disease symptoms. The developed inoculation protocol showed high performance (400 plants/h), and less space consume, when compared with other methods, mainly because it enables the inoculation of young eucalyptus seedlings (6090 days of age). In the second phase of this work, it was evaluated the eucalyptus inter-specific resistance to C. fimbriata by using the species: Eucalyptus camaldulensis, E. dunnii, E. grandis, E. pellita, E. saligna, E. tereticornis and E. urophylla. There was resistance segregation for all species and according to the origin place of the population. For $\boldsymbol{E}$. urophylla, for example, occurred the greatest variations among the number of resistant individuals and susceptible to diseases. Those variations can be linked to seed precedence and to genetic improvement program characteristics.
\end{abstract}

Keywords: Eucalyptus, Genotype screening and Resistance.

\footnotetext{
${ }^{1}$ Recebido em 29.01.2009 e aceito para publicação em 20.04.2011.

2 Fibria Celulose S.A., Centro de Tecnologia. E-mail:<rgoncalves@fibria.com.br>.

${ }^{3}$ Departamento de Fitopatologia, Universidade Federal de Viçosa, UFV, Brasil. E-mail: <aalfenas@ufv.br>.

${ }^{4}$ Departamento de Fitopatologia, Universidade Federal de Lavras, UFLA, Brasil. E-mail: E-mail: < ferreiraem@yahoo.com.br>.

${ }^{5}$ Programa de Pós-Graduação em Ciência Florestal pela Universidade Federal de Viçosa, UFV, Brasil. E-mail: <danielbinoti@yahoo.com.br>.
} 


\section{INTRODUÇÃO}

A murcha do eucalipto, causada por Ceratocystis fimbriata, é uma das principais doenças da cultura. Este fato pode ser atribuído ao potencial de causar prejuízos econômicos, aos poucos conhecimentos e às várias características do patossistema que dificultam o controle, como: i) sobrevivência do fungo no solo e, potencialmente, em resíduos da cultura, como serragem, ramos, raízes, cascas e cepas; ii) disseminação do patógeno por mudas contaminadas; iii) natureza sistêmica das infecções; e iv) potencialidade de transmissão do patógeno por ferramentas de corte e implementos florestais; o que pode aumentar substancialmente a disseminação da doença e, até mesmo, inviabilizar a condução da rebrota do eucalipto.

A murcha-de-ceratocystis é uma doença sistêmica, cujo patógeno infecta os tecidos vasculares e do raio, promovendo a descoloração do lenho. Da progressão sistêmica do patógeno surgem lesões externas ao tronco, marrom-avermelhadas, coriáceas, contínuas ou interrompidas, que evoluem para sulcadas, amarronzada, contínua e com calos longitudinais nas duas laterais (FERREIRA et al., 2006). As plantas infectadas murcham e suas folhas tendem a permanecer presas aos ramos. Outros sintomas incluem baixo desenvolvimento, surgimento de brotações epicórmicas ao longo do fuste, cancros, morte de ponteiros e, até mesmo, morte da planta. Cortes perpendiculares ao eixo principal das árvores afetadas evidenciam a descoloração radial, o que é sintoma típico da doença (ALFENAS et al., 2009).

Na América do Sul, esta doença em eucalipto foi constatada pela primeira vez no sudeste da Bahia, em 1997 (FERREIRA et al., 1999), e, recentemente, no Uruguai (BARNES et al., 2003). De forma similar, recentes relatos da doença em plantios de eucalipto no Congo e em Uganda indicam sérios níveis de mortalidade (ROUX et al., 2000; ROUX et al., 2001). Além do eucalipto, o patógeno apresenta ampla gama de hospedeiros, incluindo espécies agronômicas e florestais, como Acacia mearnsii, Coffea arabica, Colocasia esculenta, Daucus carota, Gmelina arborea, Hevea brasiliensis, Mangifera indica, Theobroma cação. Há uma grande variabilidade fisiológica na população do patógeno, de modo que determinada espécie vegetal pode ou não ser infectada por isolados do fungo oriundos de outros hospedeiros (CAB, 2001; HARRINGTON et al., 2001; BAKER et al., 2003).
A seleção e o plantio de genótipos resistentes constituem a forma mais eficiente de controle da doença em eucalipto (ZAUZA et al., 2004). Nesse caso, é fundamental dispor de protocolos eficientes para avaliação da resistência. Sendo assim, este trabalho tem como objetivo estabelecer um protocolo rápido e simples para avaliação da resistência à murcha-de-ceratocystis, considerando a atual tecnologia de produção de mudas de eucalipto. Para isso, diferentes espécies de eucalipto foram inoculadas.

\section{MATERIAL E MÉTODOS}

Os experimentos foram realizados entre meados de setembro e de dezembro de 2008, em Viçosa, Minas Gerais. Nesse período, o monitoramento das condições climáticas foi realizado diariamente e em intervalos de 30 min. A determinação da temperatura e da umidade relativa do ar foi realizada com um coletor de dados automático (Modelo CR-10X, Campbell Scientific Inc. Logan, UT, USA).

\subsection{Isolado do patógeno e preparo do inóculo}

O isolado UFV 1288 foi obtido de um clone híbrido de eucalipto (E. urophylla x E. grandis), proveniente da região de Curvelo, Minas Gerais, pelo método de sanduíches de cenoura (LAIA et al., 2000). O inóculo foi preparado com a multiplicação do fungo em meio de cultivo BDA, a $20^{\circ} \mathrm{C}$, por 15 dias. Após esse intervalo, a coleta dos esporos (conídios e ascósporos) foi realizada em água estéril por raspagem das colônias. Posteriormente, a suspensão do inóculo foi ajustada, com um hemacitômetro, para 2,5 x $10^{4}$ esporos/ml.

\subsection{Produção das mudas de eucalipto}

A comparação dos métodos de inoculação do patógeno foi realizada empregando mudas com 60 dias de idade, de um clone híbrido comercial de eucalipto (E. urophylla x E. grandis), suscetível à doença. Mudas das diferentes espécies de eucalipto e com a mesma idade foram empregadas na avaliação da resistência interespecífica. Para isso, as mudas foram produzidas em tubetes de $55 \mathrm{~cm}^{3}$ de capacidade, contendo substrato composto por uma mistura de casca de arroz carbonizada, vermiculita de granulometria média e substrato comercial (MecPlant ${ }^{\circledR}$ ) (1:1:1). O substrato de enraizamento foi enriquecido com Osmocote ${ }^{\circledR}(\mathrm{NPK}=19: 06: 10)$ e superfosfato simples, na proporção de $2 \mathrm{~kg} / \mathrm{m}^{3}$. 


\subsection{Métodos de inoculação do patógeno}

Os métodos de inoculação testados foram: i) ferimento do coleto (aproximadamente 1/3 da circunferência), com um estilete e aplicação do inóculo nesta região; ii) extirpação de 1/3 do sistema radicular e aplicação do inóculo no coleto da muda; iii) ferimento das raízes (danos mecânicos realizados com um estilete) em dois pontos ao redor do sistema radicular e aplicação do inóculo na região do coleto; e iv) aplicação do inóculo na região do coleto sem ferimento de raízes e do coleto (controle sem ferimentos). Os métodos testados foram elaborados de acordo com a praticidade de realização e para simular ferimentos, que constituem provavelmente a principal entrada de infecções do patógeno em eucalipto. Nas inoculações, $5 \mathrm{ml}$ de inóculo contendo 2,5 x $10^{4}$ esporos $/ \mathrm{ml}$ foram aplicados com uma pipeta automática. Na testemunha (grupo controle), foram aplicados, na região do coleto, $5 \mathrm{ml}$ de água destilada estéril. A avaliação foi realizada após três meses. O crescimento das plantas (altura e biomassa da parte aérea), a severidade da doença (comprimento das lesões) e o percentual de mortalidade foram quantificados. Um delineamento inteiramente casualizado foi realizado, composto por quatro métodos de inoculação, cada um repetido cinco vezes, sendo cada parcela constituída de 10 plantas.

Na segunda etapa, com o método de inoculação que permitiu maior expressão dos sintomas da doença, foram avaliadas a severidade da doença e a mortalidade das plantas em função do tempo após a inoculação. As avaliações foram realizadas após 30, 60, 90 e 120 dias da inoculação do patógeno. O delineamento foi inteiramente casualizado, composto por quatro tempos após a inoculação, cada um repetido cinco vezes, sendo cada parcela constituída de 10 plantas.

\subsection{Avaliação da resistência interespecífica}

O método de inoculação que permitiu maior expressão dos sintomas da doença foi empregado na avaliação da resistência genética das seguintes espécies e procedências (Pi): E. camaldulensis (P1 e P2), E. dunnii, E. grandis (P1 e P2), E. pellita, E. saligna (P1, P2 e P3), E. tereticornis e E. urophylla (P1, P2 e P3). Para cada espécie, foram inoculadas 98 plantas. Após 90 dias da inoculação, o comprimento da lesão foi quantificado. As médias obtidas para cada combinação entre espécie e procedência foram agrupadas de acordo com a frequência de indivíduos nas classes: altamente resistente $(0,1-3,0 \mathrm{~cm})$, resistente $(3,1-6,0 \mathrm{~cm})$, moderadamente resistente $(6,1$ - 9,0 cm), moderadamente suscetível (9,1 - 12,0 cm), suscetível (12,1 - 15,0 cm) e altamente suscetível ( $>15,1 \mathrm{~cm})$, com base no tamanho da lesão média.

\subsection{Análises estatísticas}

Os dados referentes aos métodos de inoculação foram submetidos à análise de variância (ANOVA) pelo teste F, a 5\% de probabilidade. Posteriormente, a comparação entre as médias foi realizada pelo teste de Tukey, no mesmo nível de significância, com auxílio do programa SAEG (EUCLYDES, 1997).

\section{RESULTADOS}

A média da temperatura diária variou entre 15 e $25^{\circ} \mathrm{C}$ no período de realização dos experimentos. As maiores temperaturas foram observadas em outubro de 2008. A umidade relativa do ar foi superior a $80 \%$ na maior parte do tempo. Valores inferiores de umidade relativa foram observados também nesse mês (Figura 1).

\subsection{Protocolo de inoculação do patógeno}

A inoculação por ferimento prévio do coleto resultou em maior severidade da doença, dentre todos os métodos de inoculação testados. A extensão de descoloração do lenho foi de aproximadamente $6 \mathrm{~cm}$. Os métodos de inoculação com ferimento das raízes (corte parcial e ferimento superficial) apresentaram severidade intermediária. Não foram observadas lesões típicas do patógeno na testemunha e nas plantas do tratamento de inoculação sem ferimento de raízes e do coleto (Tabela 1 ).

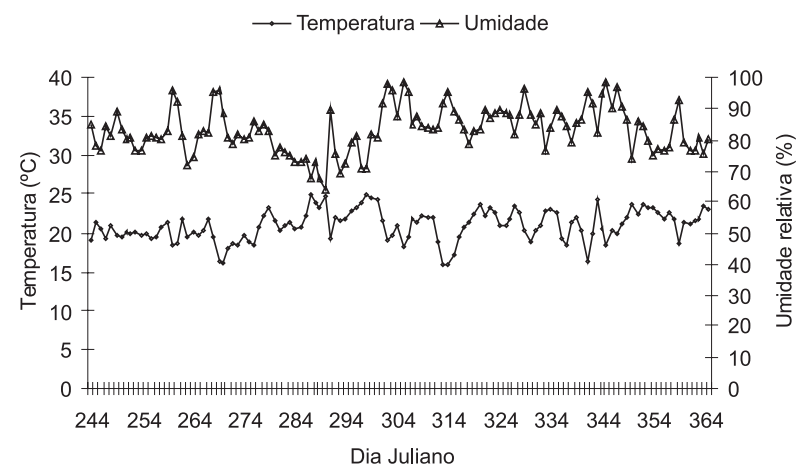

Figura 1 - Temperatura e umidade do ar diárias registradas durante os experimentos.

Figure 1 - Daily temperature and air humidity registered during the trials.

Revista Árvore, Viçosa-MG, v.35, n.4, p.817-824, 2011

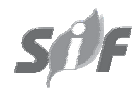


Tabela 1 - Efeito dos métodos de inoculação de Ceratocystis fimbriata sobre o crescimento de mudas e sintomas da doença. Table 1 - Effects of the inoculation methods of Ceratocystis fimbriata on growth of the seedlings and disease symptoms.

\begin{tabular}{|c|c|c|c|c|}
\hline \multirow{2}{*}{$\begin{array}{l}\text { Método de } \\
\text { inoculação }\end{array}$} & \multicolumn{2}{|c|}{ Crescimento } & \multicolumn{2}{|c|}{ Expressão da doença } \\
\hline & $\begin{array}{l}\text { Biomassa da } \\
\text { parte aérea } \\
\text { (g) }\end{array}$ & $\begin{array}{c}\text { Altura das } \\
\text { mudas } \\
(\mathrm{cm})\end{array}$ & $\begin{array}{c}\text { Lesão na } \\
\text { haste } \\
(\mathrm{cm})\end{array}$ & $\begin{array}{c}\text { Mortalidade } \\
\text { das plantas } \\
(\%)\end{array}$ \\
\hline $\begin{array}{l}\text { Controle (Testemunha - Aplicação } \\
\text { de água estéril) }\end{array}$ & 4,40 a & $38,56 \mathrm{~b}$ & $0,00 \mathrm{c}$ & 0,00 с \\
\hline $\begin{array}{l}\text { Aplicação do inóculo na região } \\
\text { do coleto sem ferimentos }\end{array}$ & 4,06 a & 47,32 a & $0,00 \mathrm{c}$ & $0,00 \mathrm{c}$ \\
\hline $\begin{array}{l}\text { Ferimento e aplicação do inóculo } \\
\text { na região do coleto }\end{array}$ & $2,66 b^{*}$ & $28,53 \mathrm{c}$ & 5,97 a & 50,79 a \\
\hline $\begin{array}{l}\text { Ferimento das raízes e aplicação } \\
\text { do inóculo na região do coleto }\end{array}$ & $2,39 \mathrm{~b}$ & 28,66 с & $3,42 \mathrm{~b}$ & $37,70 \mathrm{ab}$ \\
\hline $\begin{array}{l}\text { Corte de raízes e aplicação do } \\
\text { inóculo na região do coleto }\end{array}$ & $2,94 \mathrm{~b}$ & 28,68 c & $2,94 \mathrm{~b}$ & 23,02 bc \\
\hline
\end{tabular}

*Médias seguidas da mesma letra na coluna não diferem significativamente (teste de Tukey, $\mathrm{p} \leq 0,05$ ).

* Means followed by the same letter in a column do not differ significantly (Tukey's test, $p \leq 0,05$ ).

Os métodos de inoculação por ferimento do coleto, corte de raízes e de ferimento de raízes, seguido da aplicação do inóculo, resultaram em menor crescimento das mudas, expresso pela biomassa da parte aérea e pela altura das plantas. Para esses métodos, a biomassa da parte aérea variou de 2,4 a 2,9 mg/planta. As plantas testemunhas apresentaram, em média, 4,4 g de biomassa da parte aérea. A inoculação sem ferimento do coleto ou do sistema radicular não diferiu do controle, com média de $4,1 \mathrm{~g} /$ planta. De forma similar ao ocorrido para biomassa da parte aérea, as plantas que não foram inoculadas apresentaram maior altura, com média igual a 47,3 cm. As plantas inoculadas por ferimento do coleto ou do sistema radicular apresentaram menor altura, com média variando de 28,5 a $28,7 \mathrm{~cm}$. As plantas inoculadas sem ferimento de raízes ou do coleto apresentaram valores intermediários (38,6 cm) entre os da testemunha e os dos métodos de inoculação com ferimentos (Tabela 1).

As infecções sistêmicas resultaram em murcha das plantas, o que progressivamente evoluiu para a morte, em menor ou maior velocidade, dependendo da extensão das lesões. O método de inoculação que melhor reproduziu os sintomas da doença foi também o que causou maior mortalidade das plantas, média de 50,8\%. O método de inoculação por ferimento das raízes resultou em índice de mortalidade intermediária, não diferindo do melhor tratamento e do método de inoculação realizado com o corte de raízes. Não houve morte de plantas do grupo controle e daquelas que do método de inoculação de $C$. fimbriata, sem realização de ferimentos radiculares e do coleto (Tabela 1).
No segundo estudo, o efeito do tempo após a inoculação pelo melhor método, ou seja, ferimento do coleto e aplicação do inóculo nesta região, foi avaliado considerando a severidade da doença e a mortalidade de plantas. A mortalidade de plantas (MP) aumentou ao longo do tempo após a inoculação. A média do índice de mortalidade variou de 10 a $30 \%$ ao final dos dias avaliados: 30, 60, 90 e 120 dias. A maior severidade da doença foi também observada aos 120 dias, com o valor médio decomprimento de lesão equivalente a $8,3 \mathrm{~cm}$ (Figura 2).

\subsection{Avaliação de fontes de resistência à murcha-de- ceratocystis}

Na avaliação da resistência, constatou-se efeito da espécie e da procedência (Pi) dos genótipos testados, em relação à proporção de genótipos resistentes e suscetíveis. Dentre as espécies avaliadas, E. saligna apresentou a maior proporção de genótipos resistentes, com aproximadamente 90\% (P1) e 80\% (P2) de plantas com fenótipo moderado a altamente resistente. $E$. tereticornis apresentou aproximadamente $90 \%$ de genótipos nestas classes (Figura 3).

Houve grande variação entre as procedências de E. urophylla testadas. Por exemplo, enquanto a procedência $\mathrm{P} 1$ foi a segunda mais resistente entre todos os genótipos avaliados, a P3 foi a mais suscetível. Para E. camaldulensis também ocorreram grandes variações entre procedências (Figura 3). 


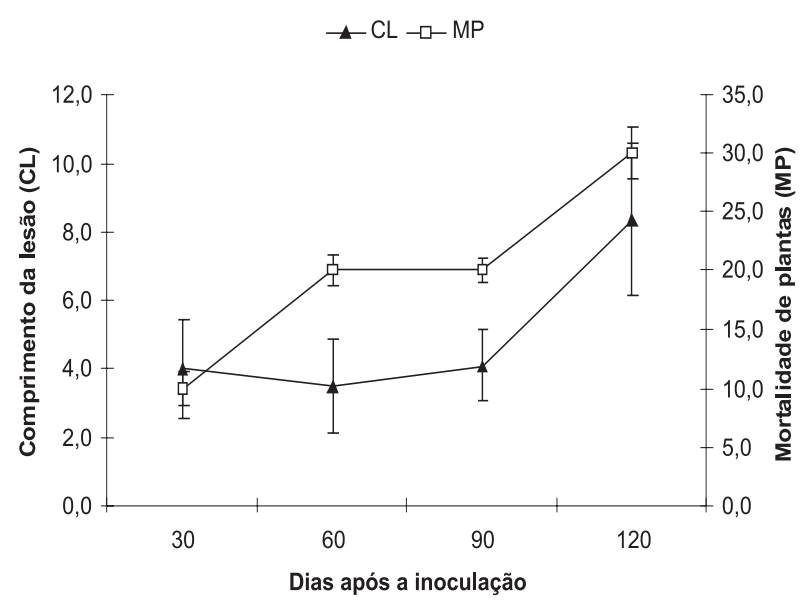

Figura 2 - Comprimento da lesão (CL) longitudinal e índice de mortalidade (MP) de plantas de eucalipto em função do tempo entre a inoculação e avaliação. As barras verticais representam o desvio padrão da média.

Figure 2 - Length of the longitudinal lesion ( $L L)$ and mortality index of plants (MI of eucalyptus plants in function of time from inoculation to evaluation. Vertical bars are standard deviation of the mean.

\section{DISCUSSÃO}

As condições e o método de inoculação de um patógeno em planta devem ser suficientemente favoráveis ao desenvolvimento e à expressão dos sintomas da doença sem, contudo, impedir a manifestação dos mecanismos de resistência constitutivos ou induzidos, decorrentes da resistência intrínseca de cada material genético (VIGOUROUX; OLIVIER, 2004). De acordo com os resultados obtidos neste trabalho, foi possível estabelecer um novo protocolo de inoculação para avaliação da resistência de eucalipto à murcha-deceratocystis. Este protocolo consiste de: i) produção das mudas em recipientes do tipo tubete; ii) inoculação das mudas com 60 dias de idade por meio de um ferimento prévio do coleto e aplicação de $5 \mathrm{ml}$ de inóculo $\left(2,5 \times 10^{4}\right.$ esporos/ml); iii) incubação das plantas por 120 dias em casa de vegetação; e iv) avaliação do número de plantas murchas ou mortas (incidência) e extensão linear da lesão no lenho (severidade). O protocolo de inoculação desenvolvido, dentre outras vantagens, apresenta alto rendimento (inoculação de 400 plantas/h), menor dispêndio de tempo e de espaço, quando comparado com os demais métodos de inoculação descritos na literatura.

Laia et al. (2000) avaliaram diferentes métodos de inoculação do patógeno e estabeleceram um protocolo para avaliação da resistência de eucalipto, que consiste basicamente da inoculação do fungo, por injeção de $1 \mathrm{ml}$ de inóculo (2,5 x $10^{6}$ esporos $\left./ \mathrm{ml}\right)$ na haste. Este método tem sido amplamente utilizado para diferentes finalidades (HARRINGTON et al., 2001; BAKER et al., 2003). Zauza et al. (2004), por exemplo, utilizaram este método para avaliação da resistência de clones de eucalipto com inoculação de mudas com oito meses

\section{Altamente resistente \\ Resistente \\ Moderadamente resistente \\ $\boxplus$ Moderamente suscetível \\ $\square$ Suscetível \\ $\square$ Altamente suscetível}

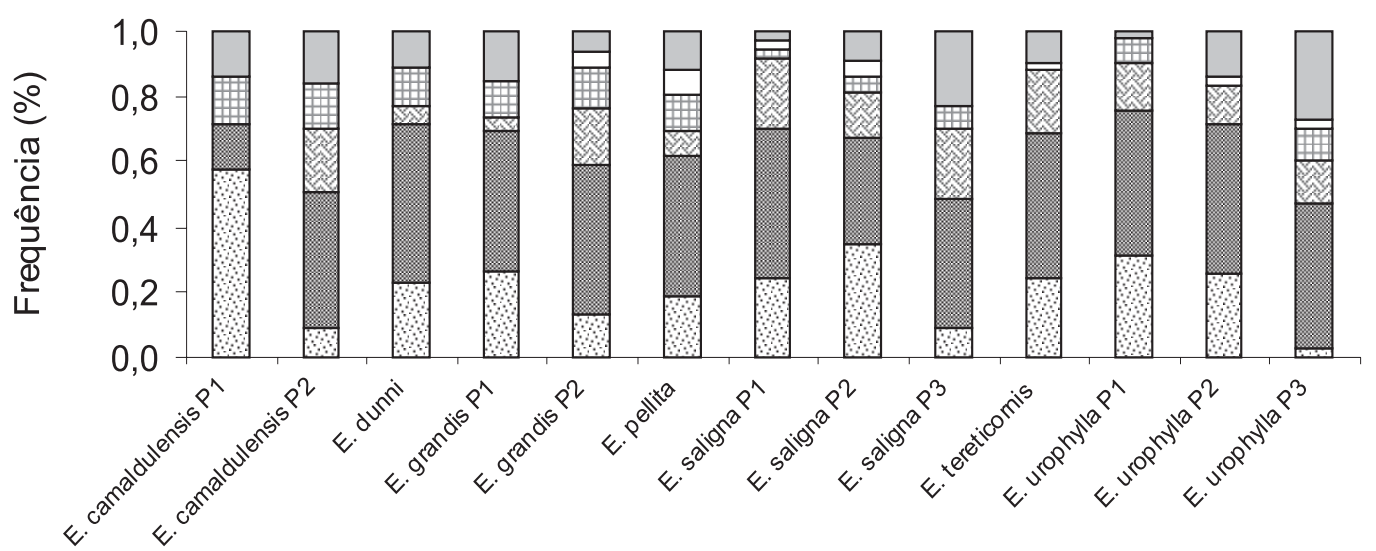

Espécies e procedências

Figura 3 - Resistência de eucalipto a murcha causada por Ceratocystis fimbriata. Figure 3 - Resistance of eucalyptus to wilt caused by Ceratocystis fimbriata. 
de idade. Por outro lado, o tempo necessário para o crescimento das plantas em vasos e o grande consumo de espaço são desvantagens desta técnica. Além disso, pode haver variações nos resultados de comprimento de lesões para um mesmo material genético. Por exemplo, para o patossitema C. fimbriata f. sp. platani e espécies de plátano (Platanus ocidentalis e Platanus orientalis), a injeção de suspensão de esporos, por meio de ferimentos frescos no hospedeiro, pode resultar no transporte passivo do inóculo por meio do sistema vascular, em função da tensão de capilaridade no interior dos vasos. Além disso, a extensão da penetração é irregular, o que, somado ao primeiro efeito, resulta em significativas variações no desenvolvimento dos sintomas (VIGOUROUX; OLIVIER, 2004).

Além do menor consumo de espaço e de tempo, o protocolo proposto neste trabalho, aparentemente, apresenta maior similaridade com as condições naturais de infecção. Assim, é pressuposto que os esporos do fungo, após a germinação, penetram através de ferimentos no sistema radicular. Os resultados observados pelo método de inoculação sem ferimento indicam que portas são fundamentais para o estabelecimento do processo infeccioso. Esses ferimentos, em condições naturais, podem ser causados por ferramentas e equipamentos utilizados no manejo da cultura (TEVIOTDALE; HARPER, 1991), bem como por ferimentos decorrentes de condições de estresse do ambiente. FERREIRA (2004), por exemplo, observou maior incidência da doença em eucalipto após os períodos de déficit hídrico, o qual pode causar rupturas do tecido radicular.

A temperatura é um dos principais fatores que interfere na interação patógeno-hospedeiro. Neste estudo, durante a realização dos experimentos, a temperatura média diária variou de 15 a $25^{\circ} \mathrm{C}$, enquanto a umidade relativa do ar foi superior a $80 \%$ na maior parte do tempo. Ainda não foram determinadas as condições favoráveis para infecção de C. fimbriata em eucalipto. Todavia, sabe-se que o fungo cresce melhor sob temperaturas variando de 18 a $28^{\circ} \mathrm{C}$. Considerando como exemplo C. fimbriata f. sp. platani, já foi determinado que o fungo não cresce em temperatura inferior a $10{ }^{\circ} \mathrm{C}$ e superior a $45^{\circ} \mathrm{C}$, e o seu máximo grau de desenvolvimento ocorre a uma temperatura de $25^{\circ} \mathrm{C}$ (EPPO/CABI, 1997). Assim, embora possam existir diferenças fisiológicas entre esses dois patógenos, acredita-se que, pelo menos, as condições de temperatura foram suficientemente favoráveis ao desenvolvimento da doença nos experimentos deste trabalho. Logo, torna-se necessário realizar estudos sobre a ecologia da interação entre o patógeno $C$. fimbriata e o eucalipto, a fim de estabelecer as condições ideais para o desenvolvimento da doença, o que pode melhorar os protocolos de avaliação da resistência. Com o conhecimento sobre melhores condições climáticas para desenvolvimento da doença, é possível manter as plantas inoculadas pelo método proposto em câmaras de crescimento, favorecendo a expressão dos sintomas da doença.

A avaliação da descoloração do lenho é empregada em diferentes protocolos para análise da resistência genética. Todavia, é de consenso que esta variável deva ser associada a outras observações, como foi realizado neste trabalho. É possível supor que alterações na coloração do lenho ocorram em locais distantes das regiões infectadas pelo patógeno, o que pode, em alguns casos, resultar em superestimação da severidade da doença. Alterações metabólicas dos tecidos vasculares de Platanus acerifolia foram observadas em pontos distantes dos locais de infecção de $C$. fimbriata f. sp. platani, em função da formação de tiloses e da deposição de géis contendo compostos fenólicos e polissacarídeos, reação típica de respostas de resistência (CLÉRIVET et al., 2000).

A seleção de genótipos deve, preferencialmente, ser realizada por um método rápido e confiável. Por exemplo, o protocolo desenvolvido com base no critério bioquímico de acumulação de fitoalexinas (EL MODAFAR et al., 1995) é questionado por Vigouroux e Oliver (2004). Segundo esses autores, o método é inadequado em função de contemplar a ação de poucos genes em detrimento de vários outros também responsáveis pela expressão da resistência. Além disso, concluem que a complexidade da relação entre plantapatógeno demanda a avaliação de vários marcadores histoquímicos. Sendo assim, o uso do critério único de tamanho de lesão não apresenta boa correlação com a suscetibilidade. Em inoculações realizadas em diferentes híbridos, as alterações visuais foram observadas acima dos pontos de inoculação, variando de 2 a mais de $10 \mathrm{~mm}$, dependendo do genótipo inoculado (VIGOUROUX et al., 1999). Com base nesses resultados, pode ser sugerido que a habilidade do patógeno em colonizar o sistema vascular está correlacionada com a produção de toxinas (AKÉ et al., 1992) e a reação dos tecidos corticais e do raio. Além dessas questões, 
é importante considerar as diferenças quanto às reações da planta em relação à colonização do sistema radicular e da parte aérea. Em plantas jovens, todas estas diferenças tornam-se irrelevantes e a avaliação tende a ser mais precisa (VIGOUROUX; OLIVIER, 2004). Neste trabalho, além de inocular plantas mais jovens, as variáveis para mortalidade e crescimento das mudas foram incluídas para aumentar a precisão das avaliações. É importante salientar que, neste método de inoculação, é possível reproduzir os sintomas de murcha, que podem resultar em morte das plantas, o que não ocorre normalmente quando se inoculam plantas mais velhas cultivadas em vasos.

O uso da resistência genética é uma das alternativas mais eficientes dentre as estratégias de controle de doenças do eucalipto, em função principalmente das características da cultura (ALFENAS et al., 2009; XAVIER et al., 2007). Sendo assim, a busca de novas fontes de resistência é fundamental para nortear os programas de cruzamentos inter e intraespecíficos, visando à transferência da característica de resistência. De acordo com os resultados obtidos neste trabalho, observaram-se variações no nível de resistência entre espécies e dentro de espécies, considerando diferentes procedências. As espécies E. dunni e E. saligna despontaram como fontes importantes de resistência, o que pode ser interessante para programas de hibridação com as espécies E. grandis e E. urophylla, as mais utilizadas nos programas de melhoramento genético.

\section{CONCLUSÕES}

Os resultados deste trabalho permitiram estabelecer um novo protocolo para avaliação da resistência de eucalipto à murcha-de-ceratocystis, o qual apresenta vantagens em relação ao método de inoculação por injeção de inóculo em plantas mantidas em vasos, como alto rendimento (inoculação de 400 plantas/h), menor consumo de espaço e de tempo para aclimatação das plantas, e possivelmente maior precisão. Além disso, E. dunni e E. saligna, das sete espécies testadas, apresentaram um bom potencial como fonte de resistência a essa doença.

\section{REFERÊNCIAS}

AKÉ, S. et al. Fimbriatan, a protein from Ceratocystis fimbriata. Phytochemistry, v.31, n.4, p.1199-1202, 1992.
ALFENAS, A. C. et al. Clonagem e doenças do eucalipto. Viçosa, MG: Universidade Federal de Viçosa, 2009. 500p.

BAKER, C. J. et al. Genetic variability and host specialization in the Latin American clade of Ceratocystis fimbriata. Phytopathology, v.93, n.10, p.1274-1284, 2003.

BARNES, I. et al. Ceratocystis fimbriata infecting Eucalyptus grandis in Uruguay. Australasian Plant Pathology, v.32, n.3, p.361-366, 2003.

CAB International. Ceratocystis fimbriata. In: Crop protection compendium. Wallingford: 2001.

CLÉRIVET, A. et al. Tyloses and gels associated with cellulose accumulation in vessels are responses of plane tree seedlings (Platanus acerifolia) to the vascular fungus Ceratocystis fimbriata f. sp. platani. Trees, v.15, n.1, p.25-31, 2000.

EL MODAFAR, C. et al. Accumulation of phytoalexins in leaves of plane tree (Platanus spp.) expressing susceptibilitiy or resistance to Ceratocystis fimbriata f. sp. platani. European Journal of Plant Pathology, v.101, n.15, p.503-509, 1995.

EPPO/CABI. Ceratocystis fimbriata f. sp. platani. In: Quarantine pests for Europe. 2.ed. Wallingford: CAB International, 1997. p.674-677.

EUCLYDES, R. F. Manual de utilização do programa SAEG (Sistema para Análises Estatística e Genética). Viçosa, MG: Universidade Federal de Viçosa, 1997. 150p.

FERREIRA, F. A. et al. Murcha de Ceratocystis em eucalipto no Brasil. Fitopatologia

Brasileira, v.24, p.284, 1999. (Suplemento).

FERREIRA, F. A. Etiologia da murcha de Ceratocystis fimbriata em eucalipto no Brasil. 2004. 68f. Tese (Doutorado em Fitopatologia) - Universidade Federal de Viçosa, Viçosa, MG, 2004.

FERREIRA, F. A. et al. Sintomatologia da murcha de Ceratocystis fimbriata em eucalipto. Revista Árvore, v.30, n.2, p.155-162, 2006.

HARRINGTON, T. C.; BAKER, C. J.; ALFENAS, A. C. Host specialization of Ceratocystis fimbriata in Brazil. Fitopatologia Brasileira, v.26, p.383, 2001.

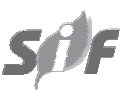

Revista Árvore, Viçosa-MG, v.35, n.4, p.817-824, 2011 
LAIA, M. L.; ALFENAS, A. C.; HARRINGTON, T.C . Isolation, detection in soil, and inoculation of Ceratocystis fimbriata, causal agent of wilting, die-back and canker in Eucalyptus (Abstract).

Fitopatologia Brasileira, v.25, p.384, 2000.

ROUX, J. et al. A serious new wilt disease of Eucalyptus caused by Ceratocystis fimbriata in Central Africa. Forest Pathology, v.30, n.3, p.175-184. 2000.

ROUX, J. et al. Diseases of plantation Eucalyptus in Uganda. South African Journal of Science, v.97, n.1, p.16-18, 2001.

TEVIOTDALE, B. L.; HARPER, D. H. Infection of pruning and small bark wounds in almond by Ceratocystis fimbriata. Plant Disease, v.75, p.1026-1030,1991
VIGOUROUX, A. et al. Canker stain of plane tree, last advances in genetic improvement for resistance. Acta Horticulture, v.496, n.1, p.99-101, 1999.

VIGOUROX, A.; OLIVIER, R. First hybrid plane trees to show resistance against canker stain (Ceratocystis fimbriata f. sp. platani). Forest Pathology, v.34, n.5, p.307-319, 2004.

XAVIER, A. A. et al. Resitência de Eucalyptus globulus e Eucalyptus nitens à ferrugem (Puccinia psidii). Revista Árvore, v.31, n.4, p.731-735, 2007.

ZAUZA, E. A. V. et al. Resistance of Eucalyptus clones to Ceratocystis fimbriata. Plant Disease, v.88, p.758-760, 2004. 